\title{
BACILLOMYCIN F, A NEW ANTIBIOTIC OF ITURIN GROUP: ISOLATION AND CHARACTERIZATION
}

\author{
Aícha Mhammedi, Françoise Peypoux, Françoise Besson \\ and GeORGES MiCHEL \\ Université Claude Bernard-Lyon I, Laboratoire de Biochimie Microbienne, \\ 43 Boulevard du 11 Novembre 1918, 69622 Villeurbanne Cédex, France
}

(Received for publication October 31, 1981)

\begin{abstract}
Bacillomycin F, a new family of iturin group antibiotics, was isolated from Bacillus subtilis. It shows a potent antifungal activity and a narrow spectrum against bacteria. Acid hydrolysis gave a peptide moiety which contains 7 mole of amino acids: D-Asp 2 , L-Glu 1 , L-Thr 1 , L-Pro ${ }_{1}$, $\mathrm{D}-\mathrm{Tyr}_{1}$ and a lipid moiety which is a mixture of two main long chain $\beta$-amino acids: 3 -amino14-methylpentadecanoic acid $(58 \%)$ and 3-amino-14-methylhexadecanoic acid $(23 \%)$.
\end{abstract}

The antibiotics of iturin group are peptidolipidic compounds characterized by a high antifungal activity $^{1 \sim 4}$. They all have a long chain $\beta$-amino acid linked to a peptidic moiety containing $\mathrm{D}$ and $\mathrm{L}$ $\alpha$-amino acids $\left.{ }^{5} \sim 8\right)$. In our work for the characterization of new antibiotics of this group, strong antifungal activity was detected in the culture broth of the strain I 164 of Bacillus subtilis.

The present paper describes the production, the purification, the antimicrobial properties and the composition of bacillomycin F.

\section{Materials and Methods}

\section{Antibiotic Production}

The antibiotic producing strain was Bacillus subtilis strain I 164, Institut Pasteur, Paris. It was grown in a medium containing $37 \mathrm{~g} /$ liter of a "brain-heart infusion" (Bio-Mérieux) at $32^{\circ} \mathrm{C}$ on a rotating shaker. A part (10\%) of this culture was used to inoculate Erlenmeyer flasks containing the production medium.

The production medium was either the medium of LANDY et al..$^{2)}$ or the medium of WALTON and WoodrufF ${ }^{2}$. The culture was carried out for 6 days at $32^{\circ} \mathrm{C}$. The production of bacillomycin $\mathrm{F}$ was followed with the bioassay procedure.

Isolation and Purification of Bacillomycin F

The broth was adjusted to $\mathrm{pH} 2.0$ with $12 \mathrm{~N} \mathrm{HCl}$. The precipitate was collected by centrifugation and extracted twice by $95 \%$ ethanol with vigorous shaking. The extracts were evaporated to dryness (yield: $1.9 \mathrm{~g} /$ liter of broth). The crude powder was dissolved in methanol and purified by column chromatography on silicic acid BioSil HA 325 mesh (BioRad, U.S.A.). Elution was performed with a discontinuous gradient of methanol in the solvent hexane - chloroform - methanol $(25: 45: 10, \mathrm{v} / \mathrm{v} / \mathrm{v})$. The antibiotic was eluted with hexane - chloroform - methanol $(25: 45: 26, \mathrm{v} / \mathrm{v} / \mathrm{v})$. A further purification was made by preparative thin-layer chromatography on silica gel with chloroform - methanol - water $(65: 25: 4, v / v / v)$, then the product was precipitated by methanol (yield $50 \mathrm{mg} / \mathrm{liter}$ of broth).

\section{Bioassay Procedure}

Antifungal activity of the ethanolic extract was determined by the cylinder method using Penicillium chrysogenum as the test organism and it was expressed by the diameters of growth inhibition zone.

The location of the antibiotic on thin-layer chromatograms was made by the detection of the antifungal activity on an agar culture of Penicillium chrysogenum. 
Determination of Antibiotic Activity

The minimal inhibitory concentration (MIC) of bacillomycin F against Gram-positive, Gramnegative bacteria, yeasts and fungi was determined by liquid or agar dilution method. MIC's were measured after 24 hours of incubation at $37^{\circ} \mathrm{C}$ for the bacteria and after three to fourteen days at $28^{\circ} \mathrm{C}$ for the yeasts and the fungi.

\section{Analytical Methods}

The infrared spectrum was recorded in $\mathrm{KBr}$ pellet on an Infracord 137 Perkin Elmer apparatus and the ultraviolet spectrum on a M25 Beckman spectrophotometer. Electrophoresis was performed on Whatman No. 1 paper in a $\mathrm{pH} 8.0$ veronal buffer for 1 hour at 45 volts $/ \mathrm{cm}$ with a Pherograph apparatus.

Water-soluble amino acids were analyzed as $N$-heptafluorobutyryl isobutyl esters ${ }^{2)}$ by gas chromatography on a capillary column of silicone WCOT SE 30 with temperature programming from $90^{\circ} \mathrm{C}$ to $290^{\circ} \mathrm{C}$ (427 Packard apparatus).

Liposoluble amino acids were analyzed as $N$-acetylmethyl esters by gas chromatography on a capillary column of silicone WCOT SE 30 from $210^{\circ} \mathrm{C}$ to $220^{\circ} \mathrm{C}$ (IGC $120 \mathrm{FL}$ Intersmat apparatus).

\section{Spectrometric Methods}

Mass spectra were obtained with a Finnigan spectrometer operating at $70 \mathrm{eV}$, using a source temperature of $240^{\circ} \mathrm{C}$, coupled with the gas chromatograph.

Hydrolysis

Total hydrolysis of bacillomycin $\mathrm{F}$ was performed with $6 \mathrm{~N} \mathrm{HCl}$ at $150^{\circ} \mathrm{C}$ for 8 hours and partial hydrolysis with $6 \mathrm{~N} \mathrm{HCl}$ at $105^{\circ} \mathrm{C}$ for 15 hours.

\section{Results}

\section{Culture Studies}

The antibiotic production tested on Penicillium chrysogenum was not related to the nature of the culture media, LANDY et al. ${ }^{2)}$ or WALTON and WoodRUFF ${ }^{3)}$ medium. The time course of the culture of B. subtilis is shown in Fig. 1. The maximum concentration of bacillomycin $\mathrm{F}$ was reached after a four days culture.

\section{Antibiotic Properties}

Bacillomycin $\mathrm{F}$ showed a strong antifungal activity against various yeasts, fungi and phytopathogenic fungi but a weak antibacterial activity only against Micrococcus luteus (Table 1).

\section{Physicochemical Properties}

Bacillomycin $\mathrm{F}$ is a colorless powder, $\mathrm{mp}$. $243^{\circ} \mathrm{C}$, giving a positive reaction with PAULY reagent. It is soluble in diluted alkali and in $75 \%$ ethanol, slightly soluble in pyridine, dimethylsulfoxide and dimethylformamide and insoluble in water and in most organic solvents.

The ultraviolet spectrum in ethanol shows absorption at $203 \mathrm{~nm}(\mathrm{Eg} / \mathrm{l}=25.2)$ and at $275 \mathrm{~nm}$ $(\mathrm{Eg} / \mathrm{l}=1.0)$. The infrared spectrum in $\mathrm{KBr}$ exhibits the bands of peptidic linkage at $3300 \mathrm{~cm}^{-1}$, $1660 \mathrm{~cm}^{-1}$ and $1550 \mathrm{~cm}^{-1}$ (Fig. 2).
Fig. 1. Time course of bacillomycin $\mathrm{F}$ production. Growth (-) was measured by the absorbance at $600 \mathrm{~nm}$ and the antifungal activity $(\mathbf{\Delta}-\mathbf{\Delta})$ was measured on Penicillium chrysogenum as described in Materials and Methods.

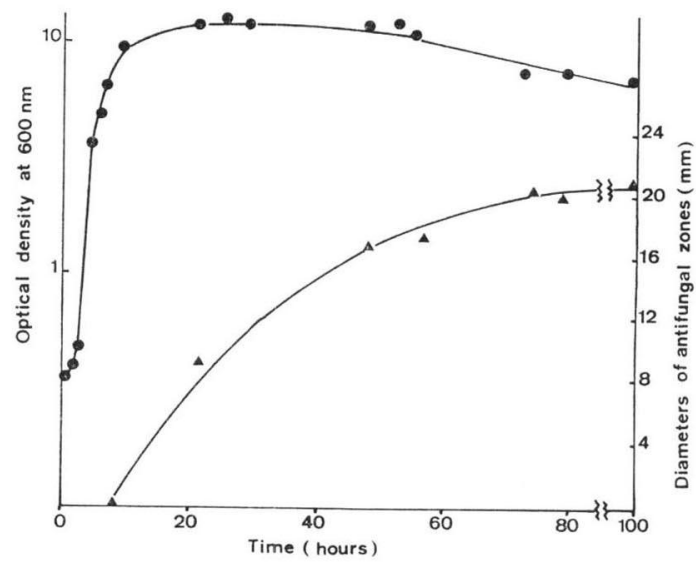


Table 1. Antimicrobial activity of bacillomycin F.

\begin{tabular}{l|r|l|r}
\hline \multicolumn{1}{c}{ Test organisms } & $\begin{array}{c}\mathrm{MIC} \\
(\mu \mathrm{g} / \mathrm{ml})\end{array}$ & \multicolumn{1}{c|}{ Test organisms } & $\begin{array}{c}\text { MIC } \\
(\mu \mathrm{g} / \mathrm{ml})\end{array}$ \\
\hline Aspergillus niger & 40 & Candida albicans & 40 \\
Botrytis cinerea (phytopathogenic) & 20 & Candida tropicalis & 40 \\
Fusarium oxysporum (phytopathogenic) & 320 & Saccharomyces cerevisiae & 10 \\
Mycosphaerella pinodes (phytopathogenic) & 10 & Azotobacter vinelandii & $>400$ \\
Neurospora crassa & 80 & Brucella bronchiseptica & $>400$ \\
Penicillium chrysogenum & 20 & Escherichia coli $\mathrm{K} 12$ & $>400$ \\
Pleospora herbarum (phytopathogenic) & 10 & Streptomyces albus $\mathrm{G}$ & $>400$ \\
Rhodotorula pilimanae & 80 & Bacillus cereus & $>400$ \\
Sclerotinia fructigena (phytopathogenic) & 40 & Micrococcus luteus & 200 \\
Sclerotinia sclerotiorum (phytopathogenic) & 50 & Sarcina lutea & $>400$ \\
Stemphylium radicinum (phytopathogenic) & 320 & Staphylococcus aureus & $>400$ \\
Trichophyton mentagrophytes & 20 & & \\
\hline
\end{tabular}

Bacteria were grown for 18 hours at $37^{\circ} \mathrm{C}$ whereas fungi were grown from 3 to 14 days at $28^{\circ} \mathrm{C}$. Phytopathogenic fungi were assayed in a medium containing tomato juice $200 \mathrm{ml}, \mathrm{CaCO}_{3} 3 \mathrm{~g}$, agar $10 \mathrm{~g}$ per liter. Yeasts and other fungi were assayed in Sabouraud medium. Streptomyces albus G was grown on peptone agar medium (biotrypcase $10 \mathrm{~g}, \mathrm{~K}_{2} \mathrm{HPO}_{4} 1 \mathrm{~g}, \mathrm{MgSO}_{4} \cdot 7 \mathrm{H}_{2} \mathrm{O} 1 \mathrm{~g}, \mathrm{NaNO}_{3} 2 \mathrm{~g}, \mathrm{KCl} 0.5 \mathrm{~g}, 2 \%$ agar). The other bacteria were tested in a brain-heart infusion medium.

Fig. 2. Infrared spectrum of bacillomycin $\mathrm{F}$ in $\mathrm{KBr}$.

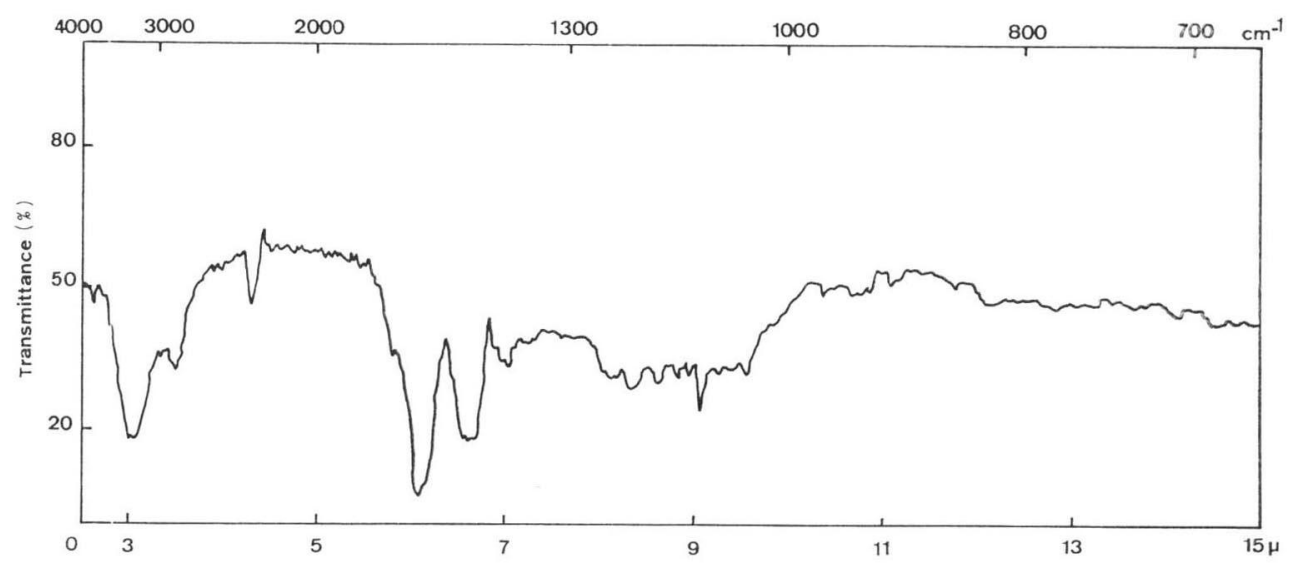

The product was tested by thin-layer chromatography on silica gel 60, $\mathrm{Rf} 0.47$ in chloroform - methanol - water $(65: 25: 4, \mathrm{v} / \mathrm{v} / \mathrm{v}), 0.63$ in dimethylformamide - water - chloroform $(44: 6: 50$, v/v/v) and 0.45 in butanol - acetone - water $(16: 24: 4, \mathrm{v} / \mathrm{v} / \mathrm{v})$. Bacillomycin $\mathrm{F}$ has no electric charge as shown by paper electrophoresis in $\mathrm{pH} 8.0$ buffer, in comparison with neutral iturin $\mathrm{A}^{7)}$ and anionic bacillomycin $\mathrm{L}^{6)}$ as standards.

\section{Analysis of Amino Acids}

Bacillomycin $\mathrm{F}$ was hydrolyzed by $6 \mathrm{~N} \mathrm{HCl}$ at $150^{\circ} \mathrm{C}$ for 8 hours. Hydrolysates were extracted with chloroform, a lipidic part and a water-soluble part were obtained.

The water-soluble amino acids were analyzed by thin-layer chromatography on cellulose powder in isopropanol - pyridine - acetic acid - water (40:40:5:20, v/v/v/v) and pyridine - tert-amylalcohol - 
water $(35: 35: 30, \mathrm{v} / \mathrm{v} / \mathrm{v})$ and identified as aspartic acid, glutamic acid, proline, threonine and tyrosine. A quantitative analysis of the $N$-heptafluorobutyryl isobutyl esters by gas chromatography gave the following molar ratios: $\mathrm{Asp}_{2.9}, \mathrm{Glu}_{1}$, $\mathrm{PrO}_{0.8}, \mathrm{Thr}_{0.7}, \mathrm{Tyr}_{1.1}$.

The configuration of the amino acids was determined by enzymatic methods ${ }^{5)}$ with $\mathrm{D}$ amino acid oxidase for proline, threonine and tyrosine, with L-glutamic decarboxylase for glutamic acid and L-glutamate oxalacetate transaminase for aspartic acid.

The amino acid composition is the following: D-Asp 2, L-Asp 1, L-Glu 1, L-Pro 1, L-Thr 1, D-Tyr ${ }_{1}$.

Analysis of the Lipid Moiety

The lipid moiety was extracted by chloroform and the yield was $28 \%$ of the initial product. Analysis by thin-layer chromatography on silica gel 60 with chloroform - methanol - water (65:
Fig. 3. Gas chromatogram of the $N$-acetyl methylesters of the lipid part of bacillomycin F.

Temperature conditions: $210^{\circ} \mathrm{C}$ for 6 minutes, then for 3 minutes from $210^{\circ} \mathrm{C}$ to $220^{\circ} \mathrm{C}$ (rate: $6^{\circ} \mathrm{C}$ per minute) and then $220^{\circ} \mathrm{C}$.

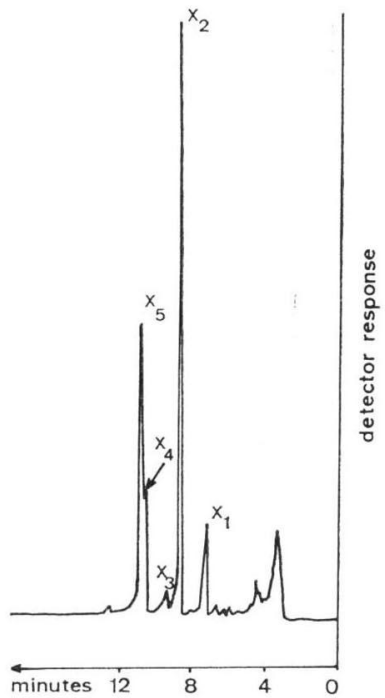

$25: 4, v / v / v)$ and detection with a ninhydrin solution according to RUSSELL ${ }^{10)}$ gave a spot with a migration identical to that of the $\beta$-amino acids obtained from iturin $A(\operatorname{Rf} 0.63)^{11)}$.

The qualitative and quantitative analysis of the lipidic compounds was carried out by gas chromatography/mass spectrometry of the $N$-acetylmethylesters. The retention times were compared with those of the $\beta$-amino acid derivatives of mycosubtilin, iturin A and of synthetic 3-aminohexadecanoic and 3-aminoheptadecanoic acids. The gas chromatogram is shown in Fig. 3.

Two main peaks $\mathrm{X}_{2}(58 \%)$ and $\mathrm{X}_{5}(23 \%)$ and three minor peaks $\mathrm{X}_{1}(6 \%), \mathrm{X}_{3}(3 \%)$ and $\mathrm{X}_{4}(10 \%)$ were observed.

The mass spectra of $X_{2}$ and $X_{5}$ are shown in Fig. 4. Two homologous molecular ions at $m / z=327$ and $m / z=341$, correspond to the derivatives $\mathrm{C}_{15} \mathrm{H}_{30}-\left(\mathrm{NH}-\mathrm{COCH}_{3}\right)-\mathrm{COOCH}_{3}\left(\mathrm{X}_{2}\right)$ and $\mathrm{C}_{10} \mathrm{H}_{32}-(\mathrm{NH}-$ $\left.\mathrm{COCH}_{3}\right)-\mathrm{COOCH}_{3}\left(\mathrm{X}_{5}\right)$ respectively. Homologous peaks at $m / z=284$ for $\mathrm{X}_{2}$ and $m / z=298$ for $\mathrm{X}_{5}$ resulting of the loss of $\mathrm{CH}_{3}-\mathrm{CO}$ from the molecular ions indicate the presence of an amide group in $\beta$ of the carboxylic ester group ${ }^{11}$.

Both spectra show the characteristic peaks of an acetamide group in $\beta$ of the carboxylic ester group. The $\alpha$ fragmentations of amide group give an ion at $m / z=144\left(\mathrm{CH}_{3}-\mathrm{CO}-\mathrm{NH}=\mathrm{CH}-\mathrm{CH}_{2}-\mathrm{COOCH}_{3}\right)^{+}$ and ions at $m / z=254\left(\mathrm{C}_{13} \mathrm{H}_{27} \mathrm{CH}=\mathrm{NH}-\mathrm{COCH}_{3}\right)^{+}$for $\mathrm{X}_{2}$ and $m / z=268\left(\mathrm{C}_{14} \mathrm{H}_{29} \mathrm{CH}=\mathrm{NH}-\mathrm{COCH}_{3}\right)^{+}$ for $\mathrm{X}_{5}$. The peak at $m / z=102\left(\mathrm{NH}=\mathrm{CH}-\mathrm{CH}_{2}-\mathrm{COOCH}_{3}\right)^{+}$arises from the loss of the ketene group from the $m / z=144$ ion.

The spectra of the derivatives $X_{1}, X_{3}$ and $X_{4}$ exhibit the molecular ions at $m / z=313,326$ and 341 , respectively. Other peaks are consistent with the derivatives of $C_{15}, C_{18}$ and $C_{17} \beta$-amino acids.

The nature of the hydrocarbon chain was determined by comparison of the retention times of $\beta$ amino acid derivatives of bacillomycin $\mathrm{F}$ and those of standard compounds. $\mathrm{X}_{1}$ was identified to 3amino-12-methyltetradecanoic acid, $\mathrm{X}_{2}$ to 3-amino-14-methylpentadecanoic acid, $\mathrm{X}_{3}$ to 3-amino-hexa- 
Fig. 4. a) Mass spectrum of the $N$-acetyl methylester of the $C_{16} \beta$ amino acid.

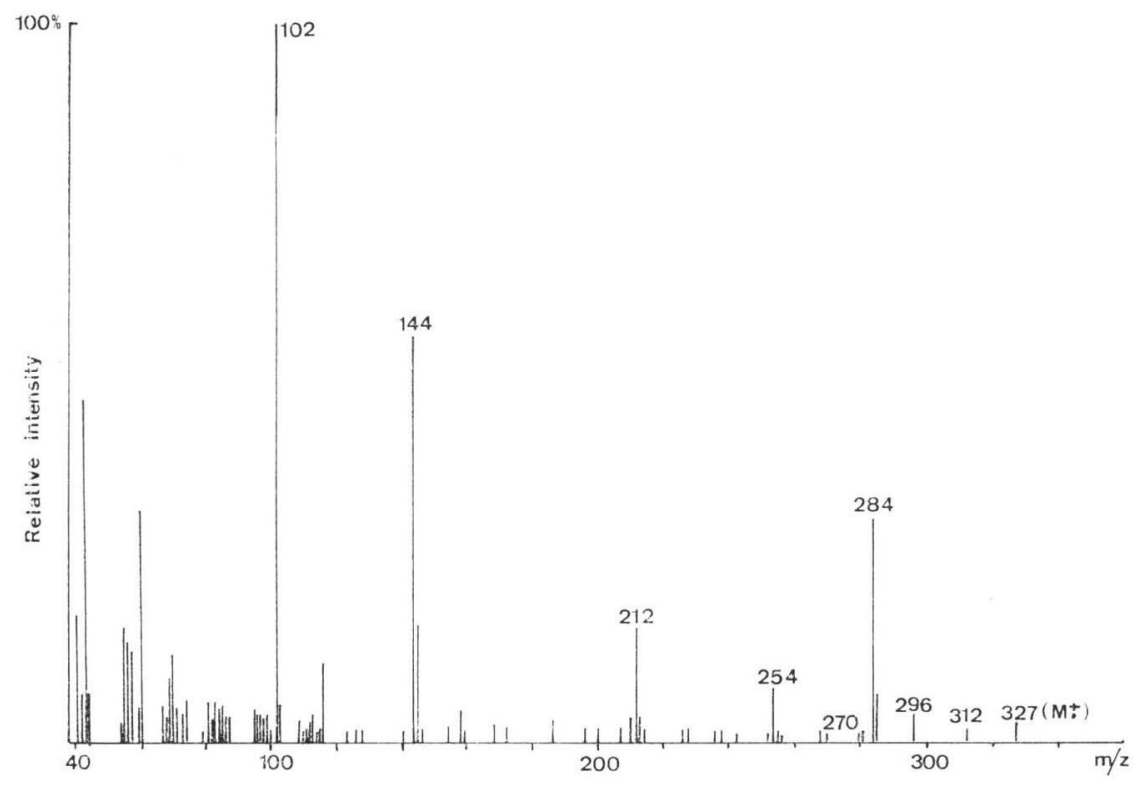

b) Mass spectrum of the $N$-acetyl methylester of the $C_{17} \beta$ amino acid.

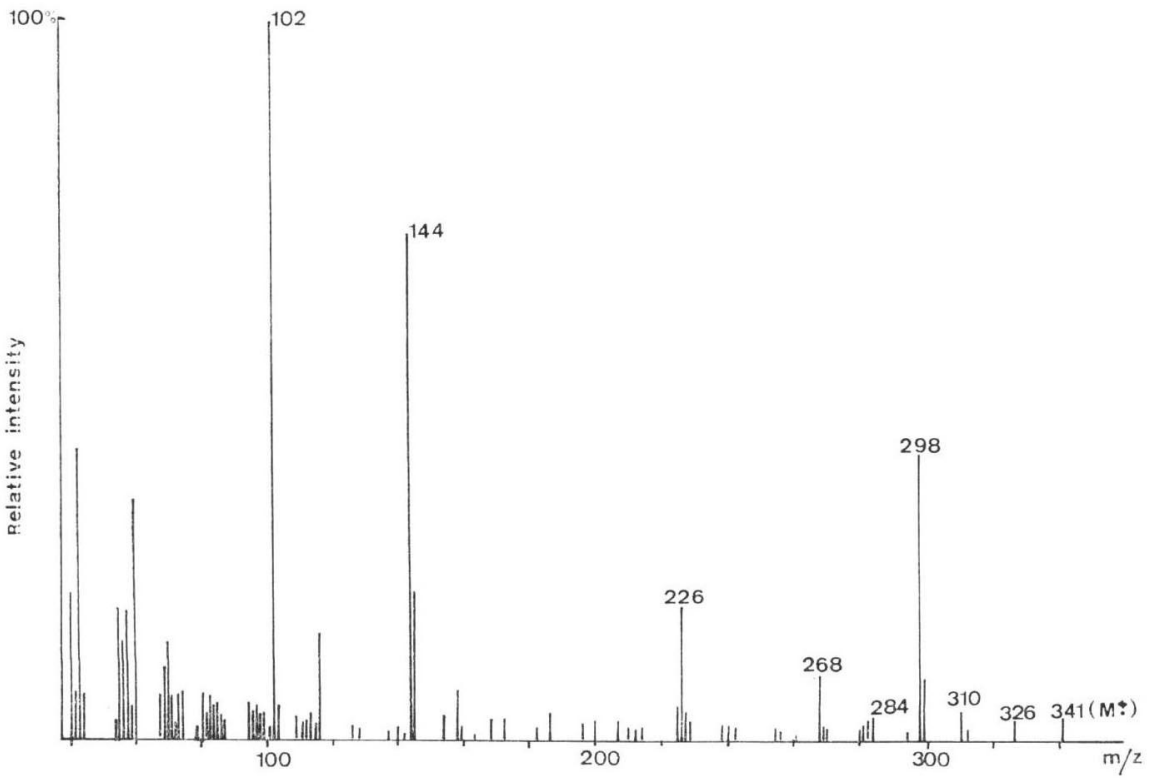

decanoic acid, $\mathrm{X}_{4}$ to 3-amino-15-methylhexadecanoic acid, $\mathrm{X}_{5}$ to 3-amino-14-methylhexadecanoic acid.

It should be noted that all $\beta$-amino acids have a chiral center at $C_{3}$ and moreover $X_{1}$ and $X_{5}$ have a second chiral center at the antepenultimate carbon atom. The configuration of these centers is not known. However, analogous $\beta$-amino acids which are constituents of iturin $\mathrm{A}$, have been found to have the $R$-configuration at the $\mathrm{C}_{3}$ center $^{12)}$. 


\section{Determination of the Peptide-lipid Linkage}

The chloroform extract of the $6 \mathrm{~N} \mathrm{HCl}$ hydrolysate at $105^{\circ} \mathrm{C}$ for 16 hours contained, besides the $\beta$ amino acids, other liposoluble compounds. Their $\operatorname{Rf}(0.40$ in chloroform - methanol - water, 65: 25: 4, $\mathrm{v} / \mathrm{v} / \mathrm{v}$ ) was identical to the $\mathrm{R} f$ of the compounds isolated in the same conditions from the hydrolysates of bacillomycin $\mathrm{L}$ and bacillomycin $\mathrm{D}$. These compounds were recovered from thin-layer plates, dinitrophenylated with 2,4-dinitrofluorobenzene and hydrolyzed by $6 \mathrm{~N} \mathrm{HCl}$ at $150^{\circ} \mathrm{C}$ for 8 hours. The hydrolysate was analyzed by thin-layer chromatography in chloroform - methanol - water $(65: 25: 4$, $\mathrm{v} / \mathrm{v} / \mathrm{v}$ ). It contained dinitrophenylthreonine ( $\mathrm{Rf} 0.37$ ) and $\beta$-amino acids ( Rf 0.63 ). Thus the compounds were threonyl- $\beta$-amino acids and the linkage between the peptide and lipid moieties is an amide bond between the carboxyl group of threonine and the amine group of a $\beta$-amino acid.

\section{Conclusions}

The present work describes the isolation of a new family of iturin group antibiotics. They were isolated from the culture broth of a strain of Bacillus subtilis by acidification and extraction with ethanol. They are potent antifungal agents and their bacterial activity are restricted to $M$. luteus as the other antibiotics of this group. The lipid moiety consists mainly of one iso- $\mathrm{C}_{10}$ or anteiso- $\mathrm{C}_{17} \beta$-amino acid as it was found in mycosubtilin belonging to iturin group ${ }^{5)}$. The amino acid composition of the peptide moiety was close to that of iturin A, with a L-threonyl residue in bacillomycin F instead of a L-seryl residue in iturin $\mathrm{A}$. This threonyl residue links the peptide moiety to the $\beta$-amino acid in bacillomycin $\mathrm{F}$ as did the seryl residue in iturin A. The structure elucidation is being continued.

\section{Acknowledgements}

This work was supported by the Centre National de la Recherche Scientifique (E. R. A. ${ }^{\circ} 852$ and A.T.P. Microbiologie 1979).

\section{References}

1) Delcambe, L. \& R. Devignat: L'iturine, nouvel antibiotique d'origine congolaise. Acad. Roy. Sc. Coloniales 6: $1 \sim 77,1957$

2) Landy, M.; G. H. Warren, S. R. Rosenman \& L. G. Colio: Bacillomycin: an antibiotic from Bacillus subtilis active against pathogenic fungi. Proc. Soc. Exp. Biol. \& Med. 67: 539 541, 1948

3) Walton, R. B. \& H. B. WoodrufF: A crystalline antifungal agent, mycosubtilin, isolated from subtilin broth. J. Clin. Invest. 28: 924 926, 1949

4) RaubitscheK, F. \& A. Dostrovsky: An antibiotic active against dermatophytes derived from Bacillus subtilis. Dermatologica 100: 45 49, 1950

5) Peypoux, F.; G. Michel \& L. Delcambe: Structure de la mycosubtiline, antibiotique isolé de Bacillus subtilis. Eur. J. Biochem. 63: 391 398, 1976

6) Besson, F.; F. Peypoux, G. Michel \& L. Delcambe: Structure de la bacillomycine L, antibiotique de Bacillus subtilis. Eur. J. Biochem. 77: 61 67, 1977

7) Peypoux, F.; M. Guinand, G. Mrchel, L. Delcambe, B. C. Das \& E. Lederer: Structure of iturin A, a peptidolipid antibiotic from Bacillus subtilis. Biochemistry 17: 3992 3996, 1978

8) Peypoux, F.; F. Besson, G. Michel \& L. Delcambe: Structure of bacillomycin D, a new antibiotic of the iturin group. Eur. J. Biochem. 118: 323 327, 1981

9) Kenzie, L. \& T. TonaschuK: Gas-liquid chromatography of $N$-heptafluorobutyryl isobutylesters of aminoacids. J. Chromatog. 97: 19 24, 1974

10) Russell, D. W.: Ninhydrin as a reagent for $N$-methylaminoacids. J. Chromatog. 4: 251 252, 1960

11) Peypoux, F.; M. Guinand, G. Michel, L. Delcambe, B. C. Das, P. Varenne \& E. Lederer: Isolement de l'acide 3-amino 12-méthyltétradécanoïque et de l'acide 3-amino 12-méthyltridécanoïque à partir de l'iturine, antibiotique de Bacillus subtilis. Tetrahedron 29: 3455 3459, 1973

12) Nagai, U.; F. Besson \& F. Peypoux: Absolute configuration of an iturinic acid as determined by CD spectrum of its DNP-p-methoxyanilide. Tetrahedron Lett. 1979: 2359 2360, 1979 